\section{Commentary: A complex tool for a simple task. Robotic AtriClip application}

\section{Leonid Sternik, MD}

I wish to congratulate authors of this interesting paper describing their experience with robotic-assisted epicardial left atrial appendage (LAA) clip application. ${ }^{1}$ It is a retrospective analysis of 42 consecutive patients who underwent robotic AtriClip application between December 2017 and September 2020. All procedures were performed by the same surgeon and by the same physician assistant at the same medical center. All transesophageal echo (TEE) examinations were reviewed by the same cardiac anesthesiologist.

The indication for the procedure was a high risk of thromboembolic stroke and intolerance to oral anticoagulants in patients with atrial fibrillation. The authors presented excellent results. No intraoperative or 30-day mortality, conversion to thoracotomy, or intraoperative complications were reported. All clips were applied satisfactorily, even in patients with pericardial adhesions. There was 1 patient with hemothorax requiring thoracoscopy a day later. TEE showed a satisfactory exclusion of appendage with LAA stump $<5 \mathrm{~mm}$ in all patients.

I am sure it is clear for all that in the patient with atrial fibrillation, especially with intolerance to oral anticoagulants, the LAA should be closed. ${ }^{2}$ To date, we do not have a perfect method and technique for LAA obliteration. Transcatheter methods including Watchman and other devices have their weaknesses. ${ }^{3}$ However, a conventional surgery for isolated LAA occlusion without any concomitant procedure seems to be too invasive. That is why the robotic thoracoscopic AtriClip application looks attractive. There

\footnotetext{
From the Department of Cardiac Surgery, Sheba Medical Center, Tel-Hashomer, Israel.

Disclosures: The author reported no conflicts of interest.

The Journal policy requires editors and reviewers to disclose conflicts of interest and to decline handling or reviewing manuscripts for which they may have a conflict of interest. The editors and reviewers of this article have no conflicts of interest.

Received for publication Aug 2, 2021; revisions received Aug 2, 2021; accepted for publication Aug 3, 2021; available ahead of print Aug 8, 2021.

Address for reprints: Leonid Sternik, MD, Department of Cardiac Surgery, Sheba Medical Center, Tel-Hashomer, Israel 52621 (E-mail: Leonid.sternik@sheba. health.gov.il).

JTCVS Techniques 2021;9:71-2

2666-2507

Copyright (C) 2021 The Author(s). Published by Elsevier Inc. on behalf of The American Association for Thoracic Surgery. This is an open access article under the CC BY-NC-ND license (http://creativecommons.org/licenses/by-nc-nd/4.0/). https://doi.org/10.1016/j.xjtc.2021.08.006
}

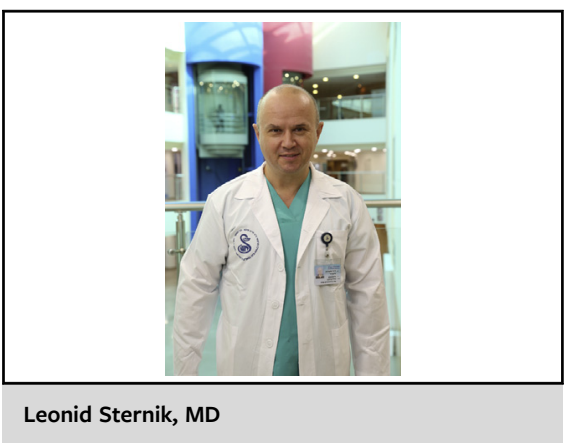

\section{CENTRAL MESSAGE \\ The simple procedure of Atriclip application done with a robot can help patients have LAA obliterated safely and efficiently and also help surgeons to become confident in robotic cardiac surgery.}

are several published series of AtriClip (AtriCure, Mason, Ohio) use in humans, with an intraoperative success rate up to $95 \%{ }^{4-6}$ The AtriClip is the only device approved by the Food and Drug Administration for surgical LAA occlusion. $^{3}$

Lewis and colleagues ${ }^{7}$ reported robotic-assisted occlusion of LAA through the right-sided approach during concomitant mitral valve surgery. A robotic surgical platform such as the da Vinci surgical system (Intuitive Surgical, Sunnyvale, Calif) may facilitate minimally invasive cardiac surgery. Cardiac surgeons have been familiar with da Vinci robot for many years. The author of this commentary worked with it more than 20 years ago. However, to date, very few cardiac surgeons use it routinely. The excellent results presented in this publication are attributed to authors' expertise and dedication. The authors were very careful with their procedure. All patients were operated by the same surgeon and physician assistant. All TEEs was interpreted by the same doctor. I hope that this paper, which describes the use of the da Vinci for a relatively simple procedure such as LAA clip application, can help patients have their LAA obliterated safely and efficiently and also may help surgeons become confident in robotic cardiac surgical procedures.

\section{References}

1. Antaki T, Michaelman J, McGroarty J. Robotics-assisted epicardial left atrial appendage clip exclusion. J Thorac Cardiovasc Surg Tech. 2021;9:59-68. 
2. Blackshear JL, Odell JA. Appendage obliteration to reduce stroke in cardiac surgical patients with atrial fibrillation. Ann Thorac Surg. 1996;61: $755-9$.

3. Glikson M, Wolff R, Hindricks G, Mandrola J, Camm J, Lip G, et al. EHRA EAPCI expert consensus statement on catheter-based left atrial appendage occlusion - an update. EuroIntervention. 2020;15:1133-80.

4. Salzberg SP, Plass A, Emmert MY, Desbiolles L, Alkadhi H, Grünenfelder J, et al. Left atrial appendage clip occlusion: early clinical results. J Thorac Cardiovasc Surg. 2010;139:1269-74.
5. Starck CT, Steffel J, Emmert MY, Plass A, Mahapatra S, Falk V, et al. Epicardial left atrial appendage clip occlusion also provides the electrical isolation of the left atrial appendage. Interact Cardiovasc Thorac Surg. 2012;15:416-8.

6. Cruz-Gonzalez I, Fuertes-Barahona M, Moreno-Samos JC, Gonzalez-Ferreiro R, Lam YY, Sanchez PL. Left atrial appendage occlusion: the current device landscape and future perspectives. Intervent Cardiol Clin. 2018;7:253-65.

7. Lewis C, Stephens R, Horst V, Angelillo M, Tyndal C. Application of an epicardial left atrial appendage occlusion device by a robotic-assisted, right chest approach. Ann Thorac Surg. 2016;101:e177-8. 